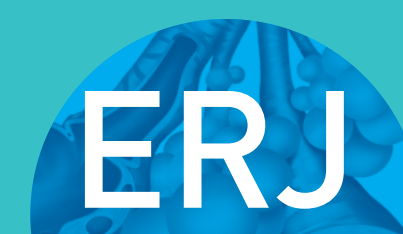

open research
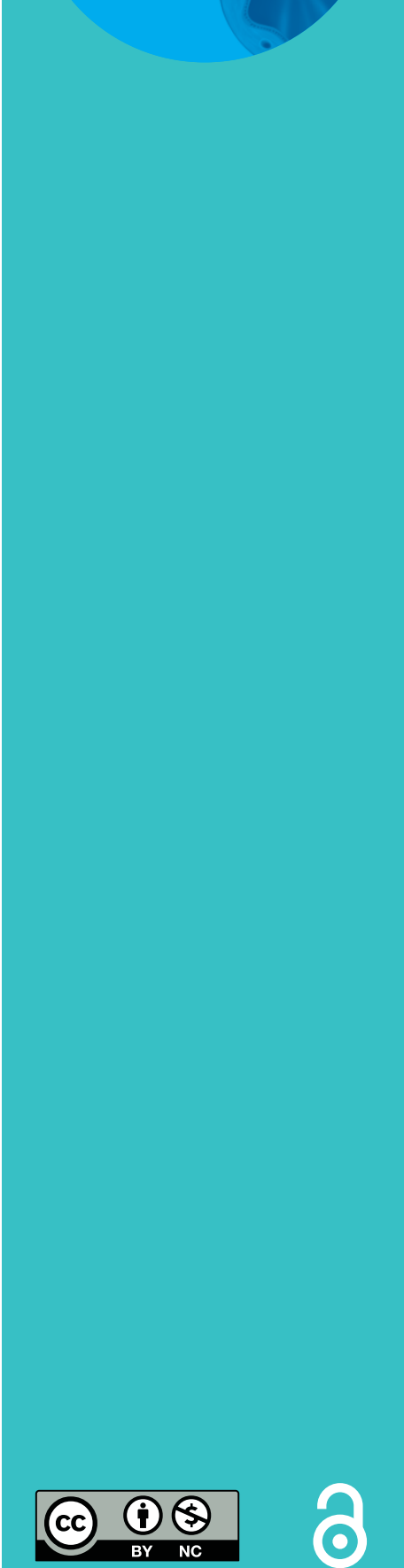

\section{Treatment of severe stable COPD: the multidimensional approach of treatable traits}

\author{
Marlies van Dijk (10 ${ }^{1,2}$, Christiaan T. Gan ${ }^{1,2}$, T. David Koster ${ }^{1,2}$, \\ Peter J. Wijkstra ${ }^{1,2}$, Dirk-Jan Slebos (1) ${ }^{1,2}$, Huib A.M. Kerstjens (1) ${ }^{1,2}$, \\ Hester van der Vaart ${ }^{1,2,3}$ and Marieke L. Duiverman (10) ${ }^{1,2}$
}

Affiliations: 'Dept of Pulmonary Diseases, University of Groningen, University Medical Center Groningen, Groningen, The Netherlands. ${ }^{2}$ Groningen Research Institute of Asthma and COPD (GRIAC), University of Groningen, Groningen, The Netherlands. ${ }^{3}$ Centre of Rehabilitation Beatrixoord, Haren, University of Groningen, University Medical Center Groningen, Groningen, The Netherlands.

Correspondence: Marlies van Dijk, Dept of Pulmonary Diseases, University Medical Center Groningen, PO Box 30001, 9700 RB Groningen, The Netherlands. E-mail: m.van.dijk05هumcg.nl

ABSTRACT Now that additional treatment options for severe chronic obstructive pulmonary disease (COPD) have emerged in recent years, patients with severe COPD should not be left in the rather hopeless situation of "there is nothing to improve" any more. Inertia or fatalism is a disservice to our patients. Ranging from advanced care planning to quite intense and demanding therapies such as multidisciplinary pulmonary rehabilitation, (endoscopic) lung volume reduction, chronic noninvasive ventilation and lung transplantation, caregivers should try to provide a personalised treatment for every severe COPD patient. In this review, we aim to describe the multidimensional approach to these patients at our centre along the lines of treatable traits leading to specific additional treatment modalities on top of standard care.

@ERSpublications

Severe COPD is not hopeless; in light of treatment options such as pulmonary rehabilitation, bronchoscopic lung volume reduction, chronic noninvasive ventilation and lung transplantation, every patient deserves a personalised assessment of treatable traits https://bit.ly/2TO7jxB

Cite this article as: van Dijk M, Gan CT, Koster TD, et al. Treatment of severe stable COPD: the multidimensional approach of treatable traits. ERJ Open Res 2020; 6: 00322-2019 [https:/doi.org/ 10.1183/23120541.00322-2019].

Received: 20 Nov 2019 | Accepted after revision: 26 May 2020

Copyright $\odot$ ERS 2020. This article is open access and distributed under the terms of the Creative Commons Attribution Non-Commercial Licence 4.0. 


\section{Introduction}

Chronic obstructive pulmonary disease (COPD) is the fourth leading cause of death worldwide [1], and the number of patients with severe end-stage COPD is still increasing. These patients often experience disabling symptoms of dyspnoea, fatigue, bad sleep, morning headache and loss of energy levels, severely impacting on their health-related quality of life (HRQoL). For a long period of time, there have been few effective treatment options for the majority of these patients. However, during the last decade, multiple treatment modalities have become more widely available. To identify the right patients for the right therapy, we believe in the concept of identifying "treatable traits" for patients, i.e. therapeutic targets identified by "phenotype" or "endotype" recognition [2, 4-]. An individual assessment of the patient helps to identify a set of treatable problems specific to this patient, and subsequently a personal treatment plan can be developed and implemented [5]. Since severe COPD is a complex and heterogeneous disease, identifying treatable traits can lead to a more effective and personalised treatment.

We aim to describe and review recent developments in the treatment of severe stable COPD, on top of standard therapy such as optimal pharmacological treatment (according to current Global Initiative for Chronic Obstructive Lung Disease (GOLD) guidelines) [1], smoking cessation, influenza vaccination and treatment of common comorbidities such as rhinitis. We will do so according to identification of treatable traits (figure 1) leading to additional treatment modalities in very severe COPD. Illustrated by a case study, we will incorporate these treatment options into a multidimensional approach. This is an approach that we have developed and is used by our dedicated severe COPD team at the University Medical Center Groningen. Written informed consent was obtained for the use of medical data for the case study, and all data were treated with confidentiality according to Good Clinical Practice guidelines.

\section{Case study}

A 55-year-old woman, with COPD GOLD classification IV/D, osteoporosis and an anxiety disorder, was referred to our outpatient clinic for assessment (table 1). She was very well motivated for additional

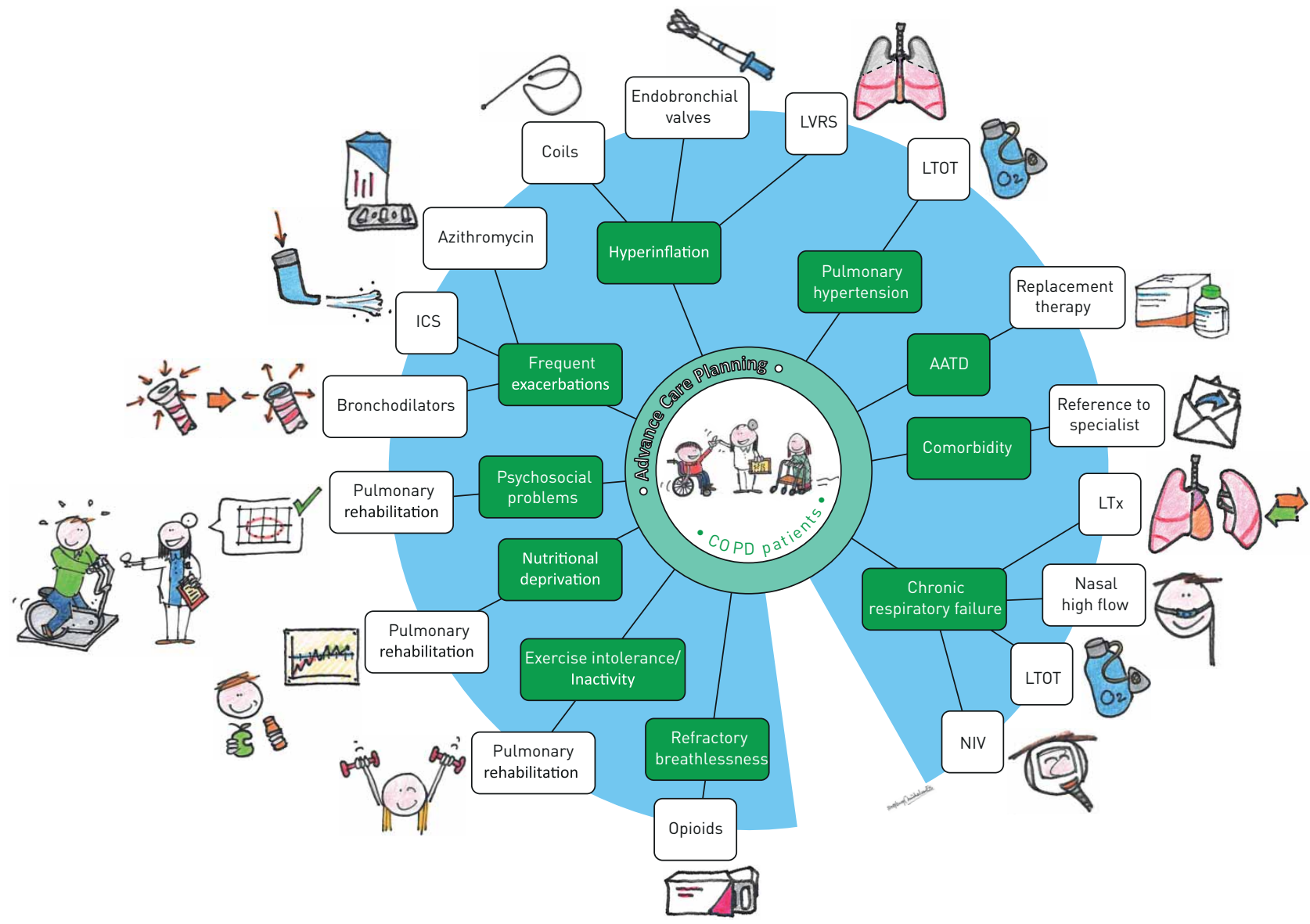

FIGURE 1 Overview of treatable traits in advanced COPD with possible treatment options. AATD: $\alpha_{1}$ antitrypsin deficiency; LVRS: lung volume reduction surgery; LTOT: long-term oxygen therapy; LTx: lung transplantation; NIV: noninvasive ventilation; ICS: inhaled corticosteroids. 
TABLE 1 Characteristics of the presented case

Case, woman, 55 years old

BMI $\mathrm{kg} \cdot \mathrm{m}^{-2}$

17

FEV $_{1} \mathrm{~L}$

FEV $1 \%$ predicted

FVC L

FVC \% predicted

FEV $_{1} /$ FVC $\%$

TLC \% predicted

RV \% predicted

RV/TLC \%

$D_{\text {LCO } \% \text { predicted }}$

$\mathrm{pH}$ at room air

$P_{\mathrm{aCO}_{2}}$ on room air $\mathrm{kPa}(\mathrm{mmHg})$

$\mathrm{P}_{\mathrm{aO}_{2}}$ on room air $\mathrm{Pa}(\mathrm{mmHg})$,

$\mathrm{HCO}_{3}^{-}$on room air mmol. $\mathrm{L}^{-1}$

6-MWD m

BMI: body mass index; $\mathrm{FEV}_{1}$ : forced expiratory volume in $1 \mathrm{~s}$; FVC: forced vital capacity; TLC: total lung capacity; $\mathrm{RV}$ : residual volume; $D_{\mathrm{Lco}}$ : diffusing capacity of the lung for carbon monoxide; $P_{\mathrm{aco}}$ : arterial carbon dioxide tension; $P_{\mathrm{aO}}$ : arterial oxygen tension; $\mathrm{HCO}_{3}^{-}$: bicarbonate; 6MWD: 6-min walk distance.

treatment options improving her HRQoL. She was evaluated during a 1-day assessment consisting of a doctor's consultation, full lung function testing, high-resolution computed tomography (HRCT) scan, arterial blood gas analysis at room air and a 6-minute walking test, and consultation with a respiratory nurse and respiratory physiotherapist. The assessment revealed that she suffered from severe dyspnoea, present in rest and increasing with exercise (modified Medical Research Council (mMRC) [6] score 3). She complained of headaches and difficulty sleeping. Furthermore, she experienced exacerbation frequently (one course of prednisone each month prescribed by the general practitioner). She had a history of 37 pack-years of smoking, but had quitted smoking 5 years ago. She was currently being treated with formoterol $24 \mu \mathrm{g}$ twice daily, beclomethasone small particles $200 \mu \mathrm{g}$ twice daily and tiotropium $18 \mu \mathrm{g}$ every day, all of which she used correctly. She also used alprazolam for anxiety and promethazine to help her sleep. Physical examination showed a cachectic woman in respiratory distress at minimal exercise. Her lung function tests showed that she had a severe airflow obstruction and severe hyperinflation. Arterial blood gas analysis showed a total respiratory failure. Her blood $\alpha 1$-a-antitrypsin level was $1.4 \mathrm{~g} \cdot \mathrm{L}^{-1}$. She was on long-term oxygen therapy (LTOT). She could walk only $125 \mathrm{~m}$ on the 6 -minute walking test. The HRCT scan revealed centrilobular emphysema in a heterogeneous distribution, with more extensive destruction in both lower lobes. Both major fissures appeared to be complete; the minor fissure was incomplete. Furthermore, the HRCT scan showed moderate central and peripheral bronchopathy with mucus plugging (figure 2)

\section{Pulmonary treatable traits in severe COPD Treatable trait: frequent exacerbations}

Exacerbations of COPD profoundly impact the patients' health status, functional capacity and lung function [7]. Especially severe exacerbations (exacerbations requiring hospitalisation) have a significant clinical and socioeconomic impact. Furthermore, having an exacerbation is an important risk factor for further exacerbations, and repeated exacerbations are associated with an increased mortality risk [8]. Therefore, it is important to prevent exacerbations by targeting modifiable risk factors ("treatable traits") for readmission, rather than treating exacerbations only when they occur.

Besides the well-known pharmacological options with long-acting bronchodilators in patients with severe COPD, the following pharmacological treatment options are of interest. Firstly, in patients with frequent exacerbations, increased blood eosinophilic level increases the likelihood of reducing exacerbation risk with inhaled corticosteroids (ICS) $[9,12-]$, thus probably representing a modifiable risk factor and treatable trait. It should be noted that the relationship between the eosinophil count and reduction in exacerbation rate is a continuous one, and therefore there is no clear cut-off point for deciding whether or not the patient could benefit from using ICS. Of note, there is no evidence that chronic use of oral corticosteroids as maintenance therapy effectively prevents exacerbations [13, 14], while the side-effects of prolonged prednisolone, such as steroid myopathy [15] and increased risk of pneumonia [16], are substantial. 


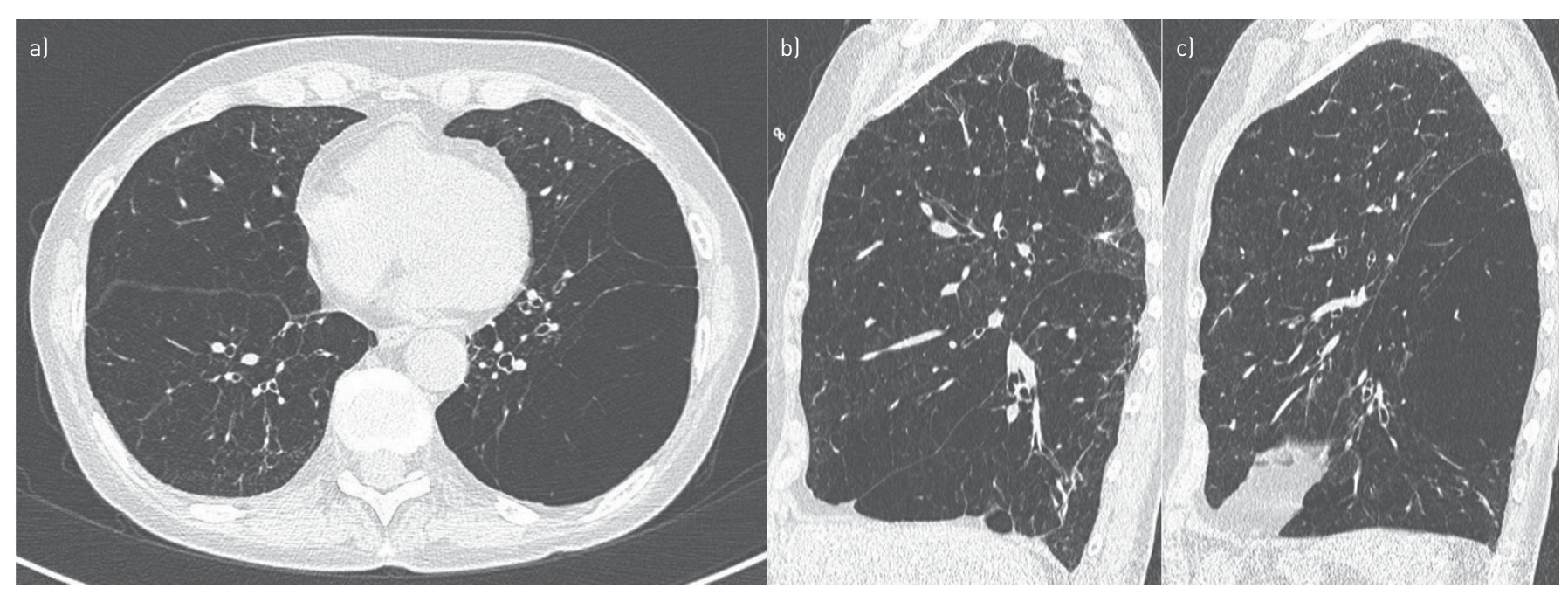

FIGURE 2 HRCT scan showing severe emphysema predominantly in the lower lobes and moderate central and peripheral bronchopathy with mucus plugging. Both major fissures appear to be complete.

Secondly, Roflumilast (a phosphodiesterase-4 inhibitor acting as an anti-inflammatory drug) has been shown to reduce the risk of severe exacerbations in patients with severe COPD and symptoms of chronic bronchitis, who have repeated exacerbations and are already on maintenance therapy with ICS, long-acting $\beta$-agonists and long-acting muscarinic antagonists $[17,18]$. However, its use might be limited by its frequent side-effects, limiting the effect on HRQoL or symptoms [19]. A more attractive alternative may be the use of macrolides (with both anti-inflammatory and anti-bacterial action) used prophylactically to reduce the rate of COPD exacerbations [20, 22-]. Disadvantages (antibiotic resistance, side-effects) should be balanced against expected benefits, and further studies are required to determine the optimal treatment regime and duration, particularly in patients with more severe COPD [23]. Furthermore, in most EU countries, the prescription of macrolides maintenance therapy is off-label.

Importantly, several non-pharmacological treatment options might be useful in preventing exacerbations. Pulmonary rehabilitation has been shown to reduce the number of exacerbations, healthcare utilisation and healthcare costs [24]. However, the direct availability of pulmonary rehabilitation post hospitalisation might be a problem because of limited resources. In patients with very severe COPD exacerbations, requiring acute noninvasive ventilation (NIV) during their exacerbation, and persistent severe post-exacerbation hypercapnia, continuing NIV nocturnally at home has been shown to increase the time to the next exacerbation and reduce subsequent exacerbation rate [25]. Chronic home nasal high-flow therapy (nHFT) is another promising option to reduce exacerbation rates in patients with frequent exacerbations [26], but evidence is limited and further trials are needed. Two bronchoscopic treatments have shown potential for exacerbation rate reduction in COPD. Targeted lung denervation (TLD) is an experimental bronchoscopic treatment disrupting parasympathetic nerves in the airways. In a recent phase II multicentre trial, the exacerbation rate during 3 to 6 months follow-up was $17.1 \%$ for the group receiving $T L D$ versus $36.6 \%$ in the group receiving sham treatment $(p=0.08)$ [27]. The underlying pathophysiological mechanism that leads to exacerbation reduction is not entirely clear but could be analogous to long-acting muscarinic antagonists, since both treatments have an anticholinergic effect. Currently, the effect of TLD on exacerbation frequency is being investigated further in a phase III multicentre sham-controlled trial (Clinical trials ID: NCT03639051). In the multicentre LIBERATE trial, patients with severe COPD and hyperinflation were randomised to receive either bronchoscopic lung volume reduction treatment with endobronchial valves or standard care. During 12 months follow-up there was a trend towards fewer exacerbations in the treatment group compared to the control group $(23 \%$ versus $30.6 \%, \mathrm{p}=0.053$ ) [28]. However, treatment with endobronchial valves is only suitable for carefully selected patients with severe emphysema and hyperinflation. The above-mentioned non-pharmacological treatment options will be discussed further in the following sections.

\section{Treatable trait: hyperinflation}

Lung volume reduction treatment has been shown to be a highly effective therapy for select patients with advanced emphysema and severe hyperinflation. By reducing hyperinflation, the function of the diaphragm and chest wall mechanics are improved, expiratory airflow increases and gas exchange can 
improve [29]. Historically, lung volume reduction was performed surgically, which is most beneficial in patients with upper lobe-predominant emphysema. Surgery is effective in some patients and shows improvement in lung function and quality of life [30]. However, the procedure is associated with risk of post-operative mortality and adverse events such as prolonged air leak. Therefore, in recent years, less invasive bronchoscopic lung volume reduction (BLVR) techniques have been developed and investigated thoroughly, among others in our centre, to achieve lung volume reduction in patients with severe emphysema and hyperinflation [31]. In general, patients with severe COPD and hyperinflation (residual volume $(\mathrm{RV})>175 \%$ predicted or RV/total lung capacity $(\mathrm{TLC}) \geqslant 0.58$ ) who are highly symptomatic despite optimal treatment are good candidates for BLVR [32]. To evaluate the possible treatment options in these patients, an HRCT scan should always be performed to assess the destruction of lung tissue, heterogeneity of emphysema and the fissure completeness.

Currently, the most important bronchoscopic options are treatment with one-way valves or endobronchial coils; both treatments are currently recommended in the COPD GOLD guidelines [1,32]. Treatment with endobronchial one-way valves has been proven to be effective in multiple randomised controlled studies, with clinically meaningful benefits in lung function, dyspnoea, quality of life and exercise tolerance [33, 37-]. Valves are placed in all (sub)segments of a target lobe to create volume reduction of this lobe. However, the treatment is only effective in patients with absence of interlobar collateral ventilation, otherwise no atelectasis of the treated lobe can occur. The presence of collateral ventilation is predicted by calculating the fissure completeness score on HRCT using quantitative computed tomography (CT)-analysis [38] and functionally measured during bronchoscopy with the Chartis system ${ }^{\circledR}$ (PulmonX Inc., Redwood City, CA, USA) [39]. If a patient is not eligible for treatment with endobronchial valves, for example due to lack of a good treatment target lobe or incomplete fissures, treatment with endobronchial coils may be considered [31, 37, 40]. Endobronchial coil placement has been shown to elicit sustained improvements in a patient's quality of life and a decrease in residual volume. However, research is ongoing to predict the optimal responders; treatment appears to be more successful in patients with an even higher baseline RV ( $>200 \%$ predicted), a higher emphysema destruction score and absence of airway disease [32]. Another treatment option in patients who are not eligible for valve treatment is bronchoscopic thermal vapour ablation. With this treatment, heated water vapour is delivered to emphysematous areas to induce an inflammatory reaction, which leads to lung volume reduction. This treatment has resulted in improvements in lung function and quality of life in patients with upper lobe-predominant emphysema [41].

\section{Treatable trait: chronic respiratory failure}

Long-term oxygen therapy

Chronic hypoxaemic respiratory failure is an indication for LTOT. In the Netherlands, it is estimated that at least 10000 patients receive LTOT each year (62/100000 inhabitants) and 2000 new patients are prescribed LTOT annually. The evidence for LTOT in COPD stems from two landmark trials performed over 40 years ago showing that LTOT prolonged life in patients with severe resting hypoxaemia versus placebo in one trial [42], and if used continuously versus only nocturnally in the other trial [42]. However, these trials were performed in very severe hypercapnic COPD patients who would probably be treated today with chronic NIV. Since then, several trials have been performed to investigate whether supplemental oxygen improves outcomes in patients with moderate hypoxaemia [43], exercise-induced desaturations and post-exacerbation hypoxaemia, and in those receiving palliative care. There may be some positive indications, for example for supplemental oxygen during exercise that improves exercise endurance and maximal exercise capacity in COPD patients with exercise-induced hypoxaemia [44, 46-], but there is no evidence that these strategies contribute to long-term clinically relevant benefits [47]. There is some rationale that particularly nocturnal hypoxaemia contributes to the development of secondary pulmonary hypertension and right heart failure, leading to a worse prognosis. The INOX trial aims to answer the question whether nocturnal oxygen provided for a period of 3 years decreases mortality or delays the prescription of LTOT in patients with COPD not qualifying for LTOT but who do have significant nocturnal arterial oxygen desaturation [48]. In our team, we evaluate oxygen therapy according to the British Thoracic Society (BTS) guidelines [49] (due to be reviewed in 2020) and additionally prescribe it during pulmonary rehabilitation in patients with exercise-induced desaturations. Of note, the way LTOT is prescribed, with a mobile device that allows patients to be ambulatory for a considerable amount of time, is extremely important in keeping patients engaged in society with optimal HRQoL.

\section{Chronic noninvasive mechanical ventilation}

When patients develop type II chronic hypercapnic respiratory failure (arterial carbon dioxide tension $\left.\left(\mathrm{Pa}_{\mathrm{CO}_{2}}\right)>6.0 \mathrm{kPa}\right)$, long-term NIV should be offered [50]. Chronic NIV in COPD has long been the subject of debate as the evidence was conflicting [51]. With the introduction of high-intensity NIV, which is defined as specific ventilator settings aimed at achieving normocapnia or the lowest $\mathrm{Pa}_{\mathrm{CO}_{2}}$ values possible [52], 
both physiological and clinical benefits of long-term NIV have been shown in patients with COPD $[25,53,59-]$. Chronic home NIV has been shown to improve survival, HRQoL, exercise tolerance and exacerbation frequency especially in patients with severe hypercapnia, both in a chronic stable state [56] and with persistent severe hypercapnia after an exacerbation [25]. Moreover, combining nocturnal NIV with a pulmonary rehabilitation programme augments the benefits of the rehabilitation, and is also the case in patients with moderate hypercapnia [54,55]. In our hospital, NIV is provided by our dedicated home mechanical ventilation team, who carefully initiate, monitor and follow-up these patients, sometimes with home visits. This dedicated approach, using an NIV setting with moderate to high pressures and a back-up respiratory rate matching the patient's respiratory rate during sleep and targeted at a substantial reduction of $\mathrm{CO}_{2}$, has resulted in successful outcomes with excellent compliance rates [55, 60,61]. However, despite this approach, not all hypercapnic patients benefit from NIV. Future research should focus on factors that predict benefit so that patients likely to gain most advantage can be selected and NIV settings optimally individualised.

\section{Nasal high-flow therapy}

nHFT supplies heated, humidified and oxygen-enriched air at high flow rates through a nasal cannula. Because the air is provided through an open system with a nasal cannula, it is relatively easy to apply and suggested to be comfortable for patients. Currently, there is growing interest in home nHFT for the treatment of chronic respiratory failure in patients with COPD $[62,63]$. Although there are some longer-term clinical studies investigating nHFT in severe COPD, the evidence is still limited, and nHFT is not standard care in many countries [64]. In hypoxaemic COPD patients, there is evidence that nHFT lowers the exacerbation rate and improves dyspnoea, $\mathrm{HRQoL}, \mathrm{Pa}_{\mathrm{CO}_{2}}$ and 6-minute walking distance, although the study was performed in a poorly defined patient group and the exacerbations were patient reported [26]. In hypercapnic COPD patients, there are some preliminary data that indicate that nHFT might be beneficial $[65,66]$, but a recent randomised controlled trial (RCT) showed only non-inferiority and no clear advantage of nHFT compared to NIV [67, 68]. As nHFT might also act positively on lung airway clearance, it would be interesting to investigate the efficacy of nHFT in the treatment of COPD exacerbations [69] and in promoting clinical stability and prevention of re-exacerbations over an extended period of time. A key problem in the application and implementation of nHFT is that the mechanisms underlying the technique are diverse, and its effect on patients in real-life situations is not clear. Furthermore, the appropriate way to apply (how many hours, day or night use?) nHFT is unknown, demonstrating the necessity of new studies. In our centre, we currently provide long-term home nHFT in clinical trials only (ClinicalTrials.gov NCT03564236).

\section{Treatable trait: $\alpha_{1}$ antitrypsin deficiency}

$\alpha_{1}$ antitrypsin deficiency (AATD) is a genetic disorder caused by a great variety of mutations in the SERPINA-1 gene. If both alleles of the gene are mutated, this can lead to AATD, with Type ZZ being the most common genotype in severe AATD [70].

The current GOLD guidelines advise screening of every COPD patient for AATD (especially in regions with a high prevalence), and not only the typical patient who is diagnosed with COPD at an early age and has lower lobe-predominant emphysema [1]. However, in clinical practice it appears that only a minority of patients with COPD are tested for AATD [71]. The first diagnostic test to diagnose AATD is usually measurement of $\alpha_{1}$ antitrypsin levels in blood. An $\alpha_{1}$ antitrypsin level lower than $1.1 \mathrm{~g} \cdot \mathrm{L}^{-1}$ is suggested as the threshold for further testing, which consists of either protein phenotyping or genotyping [72]. Notably, forced expiratory volume in $1 \mathrm{~s}\left(\mathrm{FEV}_{1}\right)$ and diffusing capacity can behave differently in AATD, and a decline in either one can be the first indication of rapid progression of the disease. Therefore, annual follow-up of both spirometry and gas transfer is important to monitor the disease [72]. AATD can also have extrapulmonary manifestations, most importantly liver disease, for which additional testing should be considered [73]. Furthermore, family members can be affected, and screening for AATD should be offered to them [1].

Since AATD is rare, patients should be referred to an expert centre for management [1]. Studies investigating AAT replacement therapy have demonstrated some effect in reducing the rate of decline in $\mathrm{FEV}_{1}$ in observational studies ( 9 to $22 \mathrm{~mL}$ lower reduction in $\mathrm{FEV}_{1}$ per year compared to controls) and progression of emphysema measured by CT densitometry in RCTs [72]. It is important to note that replacement therapy is a high-cost treatment, and availability may vary among different countries.

\section{Treatable trait: pulmonary hypertension}

Development of pulmonary hypertension $(\mathrm{PH})$ in COPD is common and has a negative impact on exercise capacity, prognosis and survival [74]. The majority of COPD patients develop $\mathrm{PH}$ with a mean pulmonary artery pressure of between 20 and $35 \mathrm{mmHg}$ [75]; only 3-4\% of patients have a mean 
pulmonary artery pressure $>35 \mathrm{mmHg}[75,76]$. It has been suggested that there is a pulmonary vascular phenotype of COPD patients. These patients have less severe airflow limitation, more severe hypoxaemia, very low diffusing capacity and cardiovascular exercise limitation $[77,78]$. It is recommended that COPD patients should be evaluated for $\mathrm{PH}$ when it has an impact on patient management, i.e. referral for lung transplantation, treatment of left heart failure or inclusion in clinical trials [79].

Although chronic hypoxaemia is an important contributor to $\mathrm{PH}$ in COPD, other factors may play a role and need to be elucidated. For example, it has been shown that vascular lesions associated with idiopathic pulmonary arterial hypertension may also be present in patients with COPD and PH [80]. Unfortunately, since it is unclear what factors contribute to the vasculopathy in COPD patients with $\mathrm{PH}$, identifying treatments to reverse $\mathrm{PH}$ in COPD remains challenging and merits further investigation.

The only recommended therapy to influence PH in COPD is long-term oxygen therapy [81]. Oxygen therapy used $>15 \mathrm{~h}$ per day obviated an increase in pulmonary artery pressure, whereas oxygen therapy used $>18 \mathrm{~h}$ per day reduced mean pulmonary artery pressure $[82,83]$. In COPD patients with $\mathrm{PH}$, there is no firm evidence that improvement of pulmonary hemodynamics with vasodilator therapy results in significant improvement of symptoms and exercise tolerance [84, 87-]. Treatment with calcium channel blockers is not advised, because of the potential deterioration of gas exchange [85, 88]. For endothelin receptor antagonists and phosphodiesterase inhibitors there are only a few and rather small randomised trials. Meta-analyses have shown a beneficial effect on pulmonary haemodynamics $[89,90]$, but there are conflicting data on the effect on exercise tolerance and disappointing results on symptoms and quality of life $[89,90]$. It is important to identify additional comorbidities leading to $\mathrm{PH}$ such as left heart failure, chronic thromboembolic disease and obesity/obstructive sleep apnoea. It is currently unknown whether chronic NIV reduces pulmonary artery pressures in COPD. NIV has been shown to reduce pulmonary artery pressure $[91,92]$, but only in a group of obesity hypoventilation patients. Furthermore, there is some evidence that lung volume reduction treatment might reverse $\mathrm{PH}$, but the current evidence is weak and only from very small studies [93].

\section{Treatable traits: extrapulmonary (colmorbidities}

\section{Exercise intolerance/deconditioning/under- or overweight/treatable behaviour}

It is commonly recognised that COPD does not only concern the respiratory system. Comorbid conditions often contribute to the phenotype and should therefore be targeted by appropriate therapies. Pulmonary rehabilitation, described as "a comprehensive intervention based on a thorough patient assessment followed by patient tailored therapies that include, but are not limited to, exercise training, education, and behavior change, designed to improve the physical and psychological condition of people with chronic respiratory disease and to promote the long-term adherence to health-enhancing behaviors" [94], has clearly been shown to increase exercise performance, reduce breathlessness and improve quality of life compared to usual care in patients with COPD [24].

In the Netherlands, different levels of reactivation and rehabilitation programmes are available for COPD patients. Depending on the GOLD stage, patients can receive supervised exercise training in primary care if the patient's main goal is to improve physical performance. Multidisciplinary outpatient rehabilitation programmes are offered and organised in hospitals and nursing homes. For the more complex patients interdisciplinary in- and outpatient rehabilitation programmes are available in specialised rehabilitation centres and paid for by all insurers. Referral for pulmonary rehabilitation is indicated for patients who experience problems in multiple domains despite optimal standard treatment.

In order to receive a personalised rehabilitation programme, a thorough assessment focusing on the physical, psychological and nutritional status of the patient has to be performed before the start of the rehabilitation programme [95]. In our rehabilitation centre, indications for other COPD-related treatments like NIV and BLVR are all addressed during the assessment.

Several aspects are of importance in the rehabilitation of very severe COPD patients. To increase exercise tolerance in these patients, strength training instead of endurance training is preferable [96]. Strength training has been shown to be equally effective as endurance training but is better tolerated due to a lower ventilatory demand. A more recent therapy is neuromuscular electrostimulation, which gives muscle contractions of the quadriceps or gastrocnemius without increase of ventilation. This therapy has been shown to improve muscle strength and endurance capacity [97]. The role of the addition of inspiratory muscle training (IMT) is controversial [94]; more recent studies failed to demonstrate an additional benefit on exercise tolerance, quality of life or dyspnoea $[98,99]$, and IMT training is quite burdensome for severe COPD patients. Therefore, we do not use this as regular care in our rehabilitation programme for severe COPD. Ventilatory assistance during exercise (with NIV or nHFT) has been shown to improve exercise capacity and endurance [100, 106-]. However, assisted exercise training is quite cumbersome, and as 
studies have not shown long-term clinically worthwhile benefits on eventual unassisted exercise capacity and patient-related outcome measures, these assistance modes of training are not widely used. Malnourishment and cachexia are seen mainly in (very) severe COPD and are important risk factors for mortality [107]. Treatment requires an interdisciplinary approach, since it is a problem that overlaps domains. Next to the dietary intervention, a physician is needed to diagnose and treat related comorbidities and prescribe anabolic steroids in selected patients [108]. A physiotherapist is needed to appoint a training modality that does not lead to further muscle loss, and a psychologist may be needed to diagnose relevant barriers and beliefs.

Surprisingly, a systematic review investigating effects of a wide range of add-on interventions to exercise training showed that there was rarely an additional effect on exercise capacity in COPD. However, as suggested by the authors, this may very well be the result of a "one size fits all" approach when selecting patients for participation in trials and probably underscores the importance of selecting suitable add-on therapies on the basis of treatable traits [109].

\section{Sleep disordered breathing}

The prevalence of sleep apnoea syndromes in COPD equals that of the population, although reported prevalence varies widely also according to disease stage $[61,110,111]$. Nevertheless, obstructive sleep apnoea in COPD can be considered an important treatable trait, as treatment with continuous positive airway pressure has been shown to improve survival in patients with severe hypoxaemic COPD [112]. As symptoms of excessive daytime sleepiness can be confounded by COPD symptoms [113, 114], we recommend performing a sleep study in the evaluation of a severe COPD patient, irrespective of symptoms of daytime sleepiness.

Once patients have concomitant cardiovascular comorbidities, central sleep apnoea (CSA) can often be identified, but treatment of CSA is in general more difficult. Importantly, COPD patients might develop nocturnal rapid eye movement (REM)-related hypoventilation caused by diaphragm malfunctioning due to its disadvantageous position. This might be confused for central hypopneas. However, pathophysiologically, the cause and thus treatment is completely different: when non-hypercapnic CSA due to heart failure co-exists, the treatment should focus on stabilisation of periodic breathing; REM-related hypoventilation due to diaphragm malfunctioning is best treated with ventilatory support. It has, however, never been shown that initiating NIV for isolated nocturnal hypoventilation is worthwhile [115]. Therefore, it is recommended to start NIV in COPD once daytime hypercapnia develops [50].

\section{Optimal treatment of treatable traits: what if it is not enough?}

Unfortunately, despite optimal treatment of treatable traits, some patients are still severely impaired. For a highly selected group of these patients, lung transplantation may be an option. Furthermore, every patient with advanced COPD could potentially benefit from a multimodality treatment for refractory dyspnoea and advance care planning (ACP).

\section{Lung transplantation for COPD}

In our centre, approximately $40 \%$ of the lung transplantations performed are for COPD. We would like to stress that a multidisciplinary approach in severe COPD is important to optimally time placement of patients on the waiting list for lung transplantation. In order to stratify who is in the window for lung transplantation, looking for treatable traits to optimise the clinical condition, prognosis and quality of life is a prerequisite in this group of patients for several reasons. Successful reduction of exacerbation frequency, pulmonary rehabilitation, NIV, lung volume reduction treatment or a combination of these might withhold a COPD patient to be referred for a lung transplantation. On the other hand, if there are no treatable traits or the interventions are ineffective, a patient should be evaluated and listed in an earlier phase. In other words, assessment and treatment of treatable traits should be seen in the light of the urgency and likelihood of lung transplantation in COPD. Although the majority of lung transplants annually are still for COPD, the introduction of the Lung Allocation Score (LAS) [116] in the USA and Europe resulted in an increased time for COPD patients (with mostly a low LAS score) on the waiting list [117]. This is mainly due to the limited ability to predict length of survival when patients are screened. In COPD patients, evaluating treatable traits might result in better timing of listing for lung transplantation. Clinical deterioration under optimal treatment of traits might emphasise the need for a lung transplantation, mirrored by a higher LAS and a shorter waiting time. Future studies are needed to support this.

The majority of patients who undergo lung transplantation have a good 1-year and long-term survival after lung transplantation [118]. Successful recovery post lung transplantation may be attributed to the potential of pulmonary rehabilitation, but randomised trials are lacking to support this [119]. In our 
rehabilitation centre, there is currently a trial investigating the effect of rehabilitation post transplantation. Despite good overall survival, the necessity of immunosuppressive drugs after lung transplantation results in comorbidities like chronic kidney failure, hypertension, diabetes, hyperlipidaemia, increased risk of infection and malignancies [118].

\section{Refractory breathlessness}

In advanced COPD, breathlessness is common despite optimal standard treatment and even with the advanced treatment options proposed above [120]. Amongst other things, breathlessness can lead to a reduced HRQoL, anxiety and social limitations [121]. Therefore, we should always consider additional non-pharmacological and pharmacological options to relieve refractory dyspnoea. Since breathlessness is a complex symptom, a combination of interventions is often needed to achieve an optimal result.

A relatively recent development is the so-called "Breathlessness service". This intervention addresses multiple domains: "breathing" (i.e. dysfunctional breathing), "thinking" (i.e. misconceptions, anxiety) and "functioning" (i.e. reduction in physical activity, self-isolation) [122]. Breathlessness services take place in the outpatient ward or at home and are usually carried out by specialist nurses or physiotherapists for a duration of 2-12 weeks. RCTs investigating these breathlessness services have shown a reduction in dyspnoea sensation and an increased sense of mastery (measured by the Chronic Respiratory Questionnaire) [122]. An easy to use help might be a hand-held fan; there is some evidence that this provides benefit in the treatment of breathlessness [123]. A systematic review showed a positive effect of low-dose opioids on breathlessness in COPD, with moderate-quality evidence for the use of systemic opioids and low-quality evidence for the use of nebulised opioids [124]. However, physicians may still be hesitant to prescribe opioids [125]. Benzodiazepines and antidepressants have not been shown to have a positive effect on breathlessness [126] but may be indicated in case of depression or anxiety.

\section{Advance care planning}

$\mathrm{ACP}$ is an intervention to enable patients to define goals and preferences for future medical treatment and care, and to discuss, record and review these preferences if appropriate [127]. There are indications that ACP can increase quality of life, improve communication between patient and healthcare giver and improve the likelihood of care being delivered in accordance with the patient's preference [128].

Despite the fact that advanced COPD is associated with a high mortality rate, a high burden of physical and psychological symptoms and reduced HRQoL, only a minority of patients receive any form of ACP $[129,130]$. Numerous barriers to start ACP have been identified. Barriers can be patient related (e.g. unpredictable disease course), healthcare professional related (e.g. fear of taking away patients' hope) or system related (e.g. perceived time constraints) [131]. Important topics to address in COPD are the unpredictable disease trajectory, prognosis, fear of breathlessness and suffocating, palliative treatment of symptoms, concerns about dying and preference of site for terminal care [132].

Although even a single conversation can lead to improved end-of-life care communication [133], ideally, $\mathrm{ACP}$ is an ongoing conversation between patient and healthcare giver. Furthermore, ACP is a process that should be directed by the patient but needs collaboration of pulmonologists, respiratory nurses, general practitioners and home care teams.

Since care systems vary widely among countries, there may not be one ideal way to organise ACP for COPD patients. Although we recognise that ACP should be discussed preferably at the outpatient clinic, in our current practice, ACP conversations are mostly initiated during or after hospital admissions for severe COPD. Nevertheless, there is a positive development where ACP is integrated in the pulmonary rehabilitation programme and, for example, in the long-term care provided by the home mechanical ventilation centre when patients are initiated on NIV. In the coming years, these initiatives need to be further extended.

\section{Summary: the multidimensional treatment approach}

Now that additional treatment options for severe COPD have emerged in recent years, patients with severe COPD should not be left in the rather hopeless situation of "there is nothing to improve" anymore. Inertia or fatalism is a disservice to our patients. Ranging from ACP to quite intense and demanding therapies such as NIV and lung transplantation, caregivers should try to provide a personalised treatment for every severe COPD patient. In our centre, we aim to use a multidimensional approach for the patients, since one or more treatment options are always available (table 2). Furthermore, treatment options should be discussed with the patient and re-evaluated and reconsidered over time. Evaluation is key to assessing whether the current situation is acceptable for the patient, or whether there is an indication for follow-up therapy [1]. 
TABLE 2 Overview of the treatable traits in severe COPD and the treatment options that can be offered

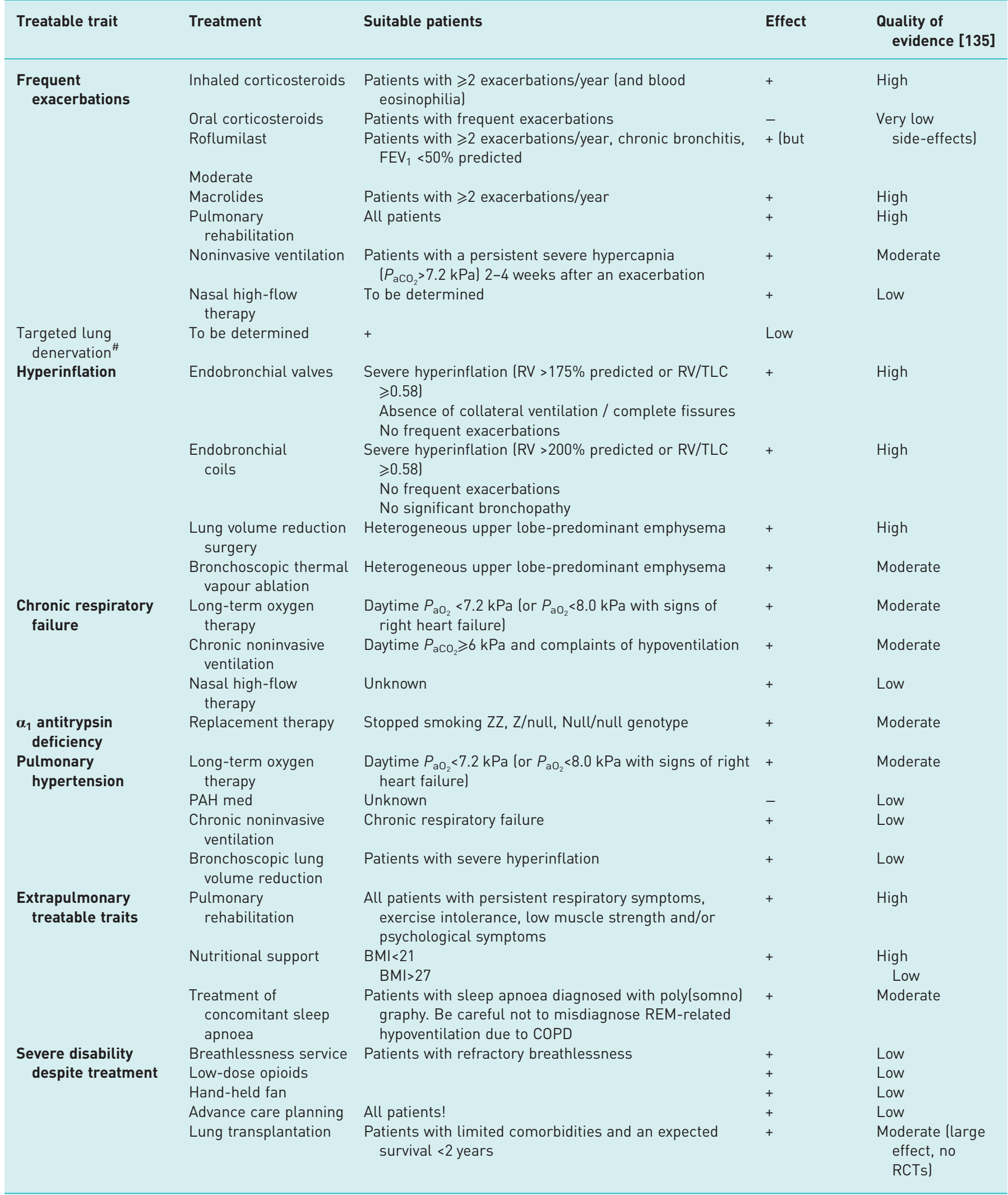

$\mathrm{FEV}_{1}$ : forced expiratory volume in $1 \mathrm{~s} ; P_{\mathrm{acO}_{2}}$ : arterial carbon dioxide tension; RV: residual volume; TLC: total lung capacity; $P_{\mathrm{aO}}$ : arterial oxygen tension; PAH: pulmonary arterial hypertension; BMI: body mass index; REM: rapid eye movements; RCTs: randomised controlled trials. ${ }^{\#}$ : Only in research setting; the level of the evidence was assessed with the GRADE system [135]. 


\section{Back to the case study}

Our patient had a COPD GOLD IV/D with severe hyperinflation, total respiratory insufficiency, frequent exacerbations, poor exercise tolerance, severe cachexia and an anxiety disorder. Available treatment options for our patient were discussed in our multidimensional respiratory failure meeting. It was clear that she needed a multidimensional approach to achieve her goal (improving HRQoL).

Because of her frequent exacerbations, the addition of azithromycin maintenance therapy was suggested. Furthermore, reducing benzodiazepines was discussed, but the patient had serious doubts about this because of anxiety and psychiatric decompensating in the past. Because of her severe hyperinflation, BLVR was discussed. However, the high exacerbation rate combined with bronchopathy on the HRCT scan made the patient ineligible for this kind of treatment at this time point. Because of the hypercapnia and complaints of morning headaches and bad sleep, the patient was thought to be a good candidate for long-term NIV, although her anxiety could be a limiting factor. Lung transplantation was discussed, and although she was not formally rejected, perioperative risks were estimated to be high because of her low body mass index. We discussed with the patient that combining NIV in a multidisciplinary rehabilitation programme, focusing on improving exercise tolerance, reducing anxiety, improving breathing techniques and gaining muscle mass, would be most suitable at this time. She was initiated on NIV prior to the pulmonary rehabilitation in our rehab centre, which she tolerated well, although she needed time and support to get used to the ventilator. Eventually, she finished this trajectory with good result.

After 2 years of home NIV, with good compliance and a reduction in exacerbation frequency, she was again discussed in our multidisciplinary meeting. Her main complaint was severe dyspnoea on minimal exertion. An HRCT scan now showed that her bronchopathy was only minimal, and her exacerbation frequency had decreased to just once a year with azithromycin maintenance therapy. Her FEV ${ }_{1}$ was stable and the RV/TLC ratio was now $73 \%$. She still tried to go to her physiotherapist for training two times a week. We decided to evaluate her again for BLVR, and she was referred for lung transplantation. Quantitative CT-analysis was performed, which revealed a destruction score of 35\% at $-950 \mathrm{HU}$ of the left lower lobe, compared to $28 \%$ of the right lower lobe, and both the right and left major fissure were $100 \%$ complete. Therefore, she was scheduled for a bronchoscopy with placement of endobronchial valves of the right lower lobe after Chartis assessment, which revealed no collateral ventilation. She obtained good and persistent results from the bronchoscopic treatment, and at 65 years of age, she finally decided to renounce lung transplantation.

Acknowledgements: We would like to thank all then other members of our severe COPD team: J.A. Nieuwenhuis, E.A.M Verschuuren, W. van der Bij, N.H.T. Ten Hacken and J. Wempe. We would also like to thank M. van Es for designing figure 1 .

Conflict of interest: M. van Dijk has nothing to disclose. C.T. Gan has nothing to disclose. T.D. Koster has nothing to disclose. P.J. Wijkstra reports grants and personal fees from Phillips; grants, personal fees and other from RESMED; grants from Vitalair; grants from VIVISOL; grants from Goedegebuure; personal fees from Synapse; and personal fees from Bresotec, all outside the submitted work. D-J. Slebos reports grants, nonfinancial support and other from PulmonX, CA, USA; grants and nonfinancial support from PneumRx/BTG, CA, USA; grants and nonfinancial support from Nuvaira, MN, USA; and nonfinancial support and other from CSA Medical, MA, USA, all outside the submitted work. H.A.M. Kerstjens has nothing to disclose. H. van der Vaart has nothing to disclose. M.L. Duiverman reports research grants and speaking fees from Philips BV, RESMED Ltd and Vivisol BV, and a research grant from Fisher and Paykel Ltd, outside the submitted work.

\section{References}

1 Global Initiative for Chronic Obstructive Lung Disease (GOLD). Global Strategy for the Diagnosis, Management and Prevention of COPD, 2018. https://goldcopd.org

2 Agusti A, Bel E, Thomas M, et al. Treatable traits: toward precision medicine of chronic airway diseases. Eur Respir J 2016; 47: 410-419.

3 Agusti A, Celli B, Faner R. What does endotyping mean for treatment in chronic obstructive pulmonary disease? Lancet 2017; 390: 980-987.

4 Celli BR, Wedzicha JA. Update on clinical aspects of chronic obstructive pulmonary disease. N Engl J Med 2019; 381: 1257-1266.

5 McDonald VM, Fingleton J, Agusti A, et al. Treatable traits: a new paradigm for 21st century management of chronic airway diseases: Treatable Traits Down Under International Workshop report. Eur Respir J 2019; 53: 1802058.

6 Mahler DA, Weinberg DH, Wells CK, et al. The measurement of dyspnea. Contents, interobserver agreement, and physiologic correlates of two new clinical indexes. Chest 1984; 85: 751-758.

7 Niewoehner DE. The impact of severe exacerbations on quality of life and the clinical course of chronic obstructive pulmonary disease. Am J Med 2006; 119: 38-45.

8 Suissa S, Dell'Aniello S, Ernst P. Long-term natural history of chronic obstructive pulmonary disease: severe exacerbations and mortality. Thorax 2012; 67: 957-963.

9 Calverley PMA, Tetzlaff K, Vogelmeier C, et al. Eosinophilia, frequent exacerbations, and steroid response in chronic obstructive pulmonary disease. Am J Respir Crit Care Med 2017; 196: 1219-1221. 

patients with chronic obstructive pulmonary disease: a post-hoc analysis of three randomised trials. Lancet Respir Med 2018; 6: 117-126.

11 Pascoe S, Barnes N, Brusselle G, et al. Blood eosinophils and treatment response with triple and dual combination therapy in chronic obstructive pulmonary disease: analysis of the IMPACT trial. Lancet Respir Med 2019; 7: 745-756.

12 van den Berge M, Kerstjens HA. Blood eosinophils as a continuous variable in the treatment of COPD: impact on the guidelines. Lancet Respir Med 2019; 7: 722-723.

13 Aaron SD, Vandemheen KL, Hebert P, et al. Outpatient oral prednisone after emergency treatment of chronic obstructive pulmonary disease. N Engl J Med 2003; 348: 2618-2625.

14 Rice KL, Rubins JB, Lebahn F, et al. Withdrawal of chronic systemic corticosteroids in patients with COPD: a randomized trial. Am J Respir Crit Care Med 2000; 162: 174-178.

15 Decramer M, Lacquet LM, Fagard R, et al. Corticosteroids contribute to muscle weakness in chronic airflow obstruction. Am J Respir Crit Care Med 1994; 150: 11-16.

16 Sivapalan P, Ingebrigtsen TS, Rasmussen DB, et al. COPD exacerbations: the impact of long versus short courses of oral corticosteroids on mortality and pneumonia: nationwide data on 67000 patients with COPD followed for 12 months. BMJ Open Respir Res 2019; 6, e000407. eCollection 2019.

17 Martinez FJ, Calverley PM, Goehring UM, et al. Effect of roflumilast on exacerbations in patients with severe chronic obstructive pulmonary disease uncontrolled by combination therapy (REACT): a multicentre randomised controlled trial. Lancet 2015; 385: 857-866.

18 Martinez FJ, Rabe KF, Sethi S, et al. Effect of roflumilast and inhaled corticosteroid/long-acting beta2-agonist on chronic obstructive pulmonary disease exacerbations (RE(2)SPOND). A randomized clinical trial. Am J Respir Crit Care Med 2016; 194: 559-567.

19 Chong J, Leung B, Poole P. Phosphodiesterase 4 inhibitors for chronic obstructive pulmonary disease. Cochrane Database Syst Rev 2017; 9: CD002309.

20 Albert RK, Connett J, Bailey WC, et al. Azithromycin for prevention of exacerbations of COPD. N Engl J Med 2011; 365: 689-698.

21 Uzun S, Djamin RS, Kluytmans JA, et al. Azithromycin maintenance treatment in patients with frequent exacerbations of chronic obstructive pulmonary disease (COLUMBUS): a randomised, double-blind, placebo-controlled trial. Lancet Respir Med 2014; 2: 361-368.

22 Herath SC, Normansell R, Maisey S, et al. Prophylactic antibiotic therapy for chronic obstructive pulmonary disease (COPD). Cochrane Database Syst Rev 2018; 10: CD009764.

23 Wedzicha JA, Calverley PMA, Albert RK, et al. Prevention of COPD exacerbations: a European Respiratory Society/American Thoracic Society guideline. Eur Respir J 2017; 50: 1602265.

24 McCarthy B, Casey D, Devane D, et al. Pulmonary rehabilitation for chronic obstructive pulmonary disease Cochrane Database Syst Rev 2015; 2: CD003793.

25 Murphy PB, Rehal S, Arbane G, et al. Effect of home noninvasive ventilation with oxygen therapy vs oxygen therapy alone on hospital readmission or death after an acute COPD exacerbation: a randomized clinical trial. JAMA 2017; 317: 2177-2186.

26 Storgaard LH, Hockey HU, Laursen BS, et al. Long-term effects of oxygen-enriched high-flow nasal cannula treatment in COPD patients with chronic hypoxemic respiratory failure. Int J Chron Obstruct Pulmon Dis 2018; 13: 1195-1205.

27 Slebos DJ, Shah PL, Herth FJ, et al. AIRFLOW-2 Trial Study Group. Safety and adverse events after targeted lung denervation for symptomatic moderate to severe COPD (AIRFLOW): a multicenter randomized controlled trial. Am J Respir Crit Care Med 2019, 200: 1477-1486.

28 Criner GJ, Sue R, Wright S, et al. A multicenter randomized controlled trial of Zephyr endobronchial valve treatment in heterogeneous emphysema (LIBERATE). Am J Respir Crit Care Med 2018; 198: 1151-1164.

29 van Agteren JE, Carson KV, Tiong LU, et al. Lung volume reduction surgery for diffuse emphysema. Cochrane Database Syst Rev 2016; 10: CD001001.

30 van Geffen WH, Slebos DJ, Herth FJ, et al. Surgical and endoscopic interventions that reduce lung volume for emphysema: a systemic review and meta-analysis. Lancet Respir Med 2019; 7: 313-324.

31 van Agteren J, Hnin K, Grosser D, et al. Bronchoscopic lung volume reduction procedures for chronic obstructive pulmonary disease. Cochrane Database Syst Rev 2017; 2: CD012158.

32 Herth FJF, Slebos DJ, Criner GJ, et al. Endoscopic lung volume reduction: an expert panel recommendation update 2019. Respiration 2019; 97: 548-557.

33 Davey C, Zoumot Z, Jordan S, et al. Bronchoscopic lung volume reduction with endobronchial valves for patients with heterogeneous emphysema and intact interlobar fissures (the BeLieVeR-HIFi study): a randomised controlled trial. Lancet 2015; 386: 1066-1073.

34 Klooster K, Ten Hacken N, Hartman J, et al. Endobronchial valves for emphysema without interlobar collateral ventilation. N Engl J Med 2015; 373: 2325-2335.

35 Kemp S, Slebos D, Kirk A, et al. A multicenter RCT of Zephyr ${ }^{\varpi}$ endobronchial valve treatment in heterogeneous emphysema (TRANSFORM). Am J Respir Crit Care Med 2017; 196: 1535-1543.

36 Valipour A, Slebos D, Herth F, et al. Endobronchial valve therapy in patients with homogeneous emphysema Results from the IMPACT study. Am J Respir Crit Care Med 2016; 194: 1073-1082.

37 Sciurba F, Criner G, Strange C, et al. Effect of endobronchial coils vs usual care on exercise tolerance in patients with severe emphysema: the RENEW Randomized Clinical Trial. JAMA 2016; 315: 2178-2189.

38 Koster T, van Rikxoort E, Huebner R, et al. Predicting lung volume reduction after endobronchial valve therapy is maximized using a combination of diagnostic tools. Respiration 2016; 92: 150-157.

39 Herth F, Eberhardt R, Gompelmann D, et al. Radiological and clinical outcomes of using Chartis ${ }^{\mathrm{TM}}$ to plan endobronchial valve treatment. Eur Respir J 2013; 41: 302-308.

40 Slebos DJ, Hartman JE, Klooster K, et al. Bronchoscopic coil treatment for patients with severe emphysema: a meta-analysis. Respiration 2015; 90: 136-145.

41 Herth FJ, Valipour A, Shah PL, et al. Segmental volume reduction using thermal vapour ablation in patients with severe emphysema: 6-month results of the multicentre, parallel-group, open-label, randomised controlled STEP-UP trial. Lancet Respir Med 2016; 4: 185-193. 
Long term domiciliary oxygen therapy in chronic hypoxic cor pulmonale complicating chronic bronchitis and emphysema. Report of the Medical Research Council Working Party. Lancet 1981; 1: 681-686. Long-Term Oxygen Treatment Trial Research Group. A randomized trial of long-term oxygen for COPD with moderate desaturation. N Engl J Med 2016; 375: 1617-1627.

Bradley JM, Lasserson T, Elborn S, et al. A systematic review of randomized controlled trials examining the short-term benefit of ambulatory oxygen in COPD. Chest 2007; 131: 278-285.

arosch I, Gloeckl R, Damm E, et al. Short-term effects of supplemental oxygen on 6-min walk test outcomes in patients with COPD: a randomized, placebo-controlled, single-blind, crossover trial. Chest 2017; 151: 795-803.

Nonoyama ML, Brooks D, Lacasse Y, et al. Oxygen therapy during exercise training in chronic obstructive pulmonary disease. Cochrane Database Syst Rev 2007; 2: CD005372.

47 Alison JA, McKeough ZJ, Leung RWM, et al. Oxygen compared to air during exercise training in COPD with exercise-induced desaturation. Eur Respir J 2019; 53: 1802429.

48 Lacasse Y, Bernard S, Series F, et al. International Nocturnal Oxygen (INOX) Research Group. Multi-center, randomized, placebo-controlled trial of nocturnal oxygen therapy in chronic obstructive pulmonary disease: a study protocol for the INOX trial. BMC Pulm Med 2017; 17: 8-016-0343-9.

49 Hardinge M, Annandale J, Bourne S, et al. British Thoracic Society Standards of Care Committee. British Thoracic Society guidelines for home oxygen use in adults. Thorax 2015; 70: Suppl. 1, i1-43.

50 Ergan B, Oczkowski S, Rochwerg B, et al. European Respiratory Society guidelines on long-term home non-invasive ventilation for management of COPD. Eur Respir J 2019; 54: 1901003.

51 Struik FM, Lacasse Y, Goldstein RS, et al. Nocturnal noninvasive positive pressure ventilation in stable COPD: a systematic review and individual patient data meta-analysis. Respir Med 2014; 108: 329-337.

52 Windisch W, Storre JH, Kohnlein T. Nocturnal non-invasive positive pressure ventilation for COPD. Expert Rev Respir Med 2015; 9: 295-308.

53 Dreher M, Storre JH, Schmoor C, et al. High-intensity versus low-intensity non-invasive ventilation in patients with stable hypercapnic COPD: a randomised crossover trial. Thorax 2010; 65: 303-308.

54 Duiverman ML, Wempe JB, Bladder G, et al. Nocturnal non-invasive ventilation in addition to rehabilitation in hypercapnic patients with COPD. Thorax 2008; 63: 1052-1057.

55 Duiverman ML, Wempe JB, Bladder G, et al. Two-year home-based nocturnal noninvasive ventilation added to rehabilitation in chronic obstructive pulmonary disease patients: a randomized controlled trial. Respir Res 2011; 12: 112 .

56 Kohnlein T, Windisch W, Kohler D, et al. Non-invasive positive pressure ventilation for the treatment of severe stable chronic obstructive pulmonary disease: a prospective, multicentre, randomised, controlled clinical trial. Lancet Respir Med 2014; 2: 698-705.

57 Windisch W, Vogel M, Sorichter S, et al. Normocapnia during nIPPV in chronic hypercapnic COPD reduces subsequent spontaneous PaCO2. Respir Med 2002; 96: 572-579.

58 Windisch W, Kostic S, Dreher M, et al. Outcome of patients with stable COPD receiving controlled noninvasive positive pressure ventilation aimed at a maximal reduction of $\mathrm{Pa}(\mathrm{CO} 2)$. Chest 2005; 128: 657-662.

59 Windisch W, Dreher M, Storre JH, et al. Nocturnal non-invasive positive pressure ventilation: physiological effects on spontaneous breathing. Respir Physiol Neurobiol 2006; 150: 251-260.

60 van der Leest S, Duiverman ML. High-intensity non-invasive ventilation in stable hypercapnic COPD: evidence of efficacy and practical advice. Respirology 2018; 24: 318-328.

61 Duiverman ML, Vonk JM, Bladder G, et al. Home initiation of chronic non-invasive ventilation in COPD patients with chronic hypercapnic respiratory failure: a randomised controlled trial. Thorax 2019; 75: $244-252$.

62 Braunlich J, Kohler M, Wirtz H. Nasal highflow improves ventilation in patients with COPD. Int J Chron Obstruct Pulmon Dis 2016; 11: 1077-1085.

63 Pisani L, Fasano L, Corcione N, et al. Change in pulmonary mechanics and the effect on breathing pattern of high flow oxygen therapy in stable hypercapnic COPD. Thorax 2017; 72: 373-375.

64 Elshof J, Duiverman ML. Clinical evidence of nasal high-flow therapy in chronic obstructive pulmonary disease patients. Respiration 2020; 99: 140-153.

65 Braunlich J, Seyfarth HJ, Wirtz H. Nasal high-flow versus non-invasive ventilation in stable hypercapnic COPD: a preliminary report. Multidiscip Respir Med 2015; 10: 27.

66 Nagata K, Kikuchi T, Horie T, et al. Domiciliary high-flow nasal cannula oxygen therapy for stable hypercapnic COPD patients: a multicenter, randomized crossover trial. Ann Am Thorac Soc 2018; 15: 432-439.

67 Braunlich J, Dellweg D, Bastian A, et al. Nasal high-flow versus noninvasive ventilation in patients with chronic hypercapnic COPD. Int J Chron Obstruct Pulmon Dis 2019; 14: 1411-1421.

68 Elshof J, Duiverman ML. Letter to the editor: "Nasal high-flow versus non-invasive ventilation in patients with chronic hypercapnic COPD” [Letter]. Int J Chron Obstruct Pulmon Dis 2019; 14: 2117-2118.

69 Pilcher J, Eastlake L, Richards M, et al. Physiological effects of titrated oxygen via nasal high-flow cannulae in COPD exacerbations: a randomized controlled cross-over trial. Respirology 2017; 22: 1149-1155.

70 Fregonese L, Stolk J. Hereditary alpha-1-antitrypsin deficiency and its clinical consequences. Orphanet J Rare Dis 2008; 3, 16

71 Soriano JB, Lucas SJ, Jones R, et al. Trends of testing for and diagnosis of alphal-antitrypsin deficiency in the UK: more testing is needed. Eur Respir J 2018; 52: 1800360.

72 Miravitlles M, Dirksen A, Ferrarotti I, et al. European Respiratory Society statement: diagnosis and treatment of pulmonary disease in alpha1-antitrypsin deficiency. Eur Respir J 2017; 50: 1700610.

73 Nelson DR, Teckman J, Di Bisceglie AM, et al. Diagnosis and management of patients with alpha1-antitrypsin (A1AT) deficiency. Clin Gastroenterol Hepatol 2012; 10: 575-580.

74 Chaouat A, Bugnet AS, Kadaoui N, et al. Severe pulmonary hypertension and chronic obstructive pulmonary disease. Am J Respir Crit Care Med 2005; 172: 189-194.

75 Chaouat A, Naeije R, Weitzenblum E. Pulmonary hypertension in COPD. Eur Respir J 2008; 32: 1371-1385.

76 Weitzenblum E, Chaouat A. Severe pulmonary hypertension in COPD: is it a distinct disease? Chest 2005; 127: 1480-1482.

77 Boerrigter BG, Bogaard HJ, Trip P, et al. Ventilatory and cardiocirculatory exercise profiles in COPD: the role of pulmonary hypertension. Chest 2012; 142: 1166-1174. 
Rose L, Prins KW, Archer SL, et al. Survival in pulmonary hypertension due to chronic lung disease: influence of low diffusion capacity of the lungs for carbon monoxide. J Heart Lung Transplant 2019; 38: 145-155.

Nathan SD, Barbera JA, Gaine SP, et al. Pulmonary hypertension in chronic lung disease and hypoxia. Eur Respir J 2019; 53: 1801914

Carlsen J, Hasseriis Andersen K, Boesgaard S, et al. Pulmonary arterial lesions in explanted lungs after transplantation correlate with severity of pulmonary hypertension in chronic obstructive pulmonary disease. $J$ Heart Lung Transplant 2013; 32: 347-354.

Galie N, Humbert M, Vachiery J-L, et al. 2015 ESC/ERS Guidelines for the diagnosis and treatment of pulmonary hypertension. The Joint Task Force for the Diagnosis and Treatment of Pulmonary Hypertension of the European Society of Cardiology (ESC) and the European Respiratory Society (ERS). Eur Respir J 2015; 46 903-975.

Weitzenblum E, Sautegeau A, Ehrhart M, et al. Long-term oxygen therapy can reverse the progression of pulmonary hypertension in patients with chronic obstructive pulmonary disease. Am Rev Respir Dis 1985; 131: 493-498.

Timms RM, Khaja FU, Williams GW. Hemodynamic response to oxygen therapy in chronic obstructive pulmonary disease. Ann Intern Med 1985; 102: 29-36.

Barnes H, Brown Z, Burns A, et al. Phosphodiesterase 5 inhibitors for pulmonary hypertension. Cochrane Database Syst Rev 2019; 1: CD012621.

Blanco I, Gimeno E, Munoz PA, et al. Hemodynamic and gas exchange effects of sildenafil in patients with chronic obstructive pulmonary disease and pulmonary hypertension. Am J Respir Crit Care Med 2010; 181: 270-278.

Blanco I, Santos S, Gea J, et al. Sildenafil to improve respiratory rehabilitation outcomes in COPD: a controlled trial. Eur Respir J 2013; 42: 982-992.

Goudie AR, Lipworth BJ, Hopkinson PJ, et al. Tadalafil in patients with chronic obstructive pulmonary disease: a randomised, double-blind, parallel-group, placebo-controlled trial. Lancet Respir Med 2014; 2: 293-300.

Barbera JA, Roger N, Roca J, et al. Worsening of pulmonary gas exchange with nitric oxide inhalation in chronic obstructive pulmonary disease. Lancet 1996; 347: 436-440.

Chen X, Tang S, Liu K, et al. Therapy in stable chronic obstructive pulmonary disease patients with pulmonary hypertension: a systematic review and meta-analysis. J Thorac Dis 2015; 7: 309-319.

Prins KW, Duval S, Markowitz J, et al. Chronic use of PAH-specific therapy in World Health Organization Group III Pulmonary Hypertension: a systematic review and meta-analysis. Pulm Circ 2017; 7: 145-155.

Schonhofer B, Barchfeld T, Wenzel M, et al. Long term effects of non-invasive mechanical ventilation on pulmonary haemodynamics in patients with chronic respiratory failure. Thorax 2001; 56: 524-528.

Held M, Walthelm J, Baron S, et al. Functional impact of pulmonary hypertension due to hypoventilation and changes under noninvasive ventilation. Eur Respir J 2014; 43: 156-165.

Bugalho A. Is endoscopic lung volume reduction able to reverse pulmonary hypertension in patients with severe emphysema? Respiration 2015; 89: 12-14.

Spruit MA, Singh SJ, Garvey C, et al. An official American Thoracic Society/European Respiratory Society statement: key concepts and advances in pulmonary rehabilitation. Am J Respir Crit Care Med 2013; 188 e13-e64.

Wouters EFM, Wouters BBREF, Augustin IML, et al. Personalised pulmonary rehabilitation in COPD. Eur Respir Rev 2018; 27: 170125.

Sillen MJ, Franssen FM, Delbressine JM, et al. Efficacy of lower-limb muscle training modalities in severely dyspnoeic individuals with COPD and quadriceps muscle weakness: results from the DICES trial. Thorax 2014 69: 525-531.

Chen RC, Li XY, Guan LL, et al. Effectiveness of neuromuscular electrical stimulation for the rehabilitation of moderate-to-severe COPD: a meta-analysis. Int J Chron Obstruct Pulmon Dis 2016; 11: 2965-2975.

Beaumont M, Mialon P, Le Ber C, et al. Effects of inspiratory muscle training on dyspnoea in severe COPD patients during pulmonary rehabilitation: controlled randomised trial. Eur Respir J 2018; 51: 1701107.

Schultz K, Jelusic D, Wittmann M, et al. Inspiratory muscle training does not improve clinical outcomes in 3-week COPD rehabilitation: results from a randomised controlled trial. Eur Respir J 2018; 51: 1702000.

Dreher M, Storre JH, Windisch W. Noninvasive ventilation during walking in patients with severe COPD: a randomised cross-over trial. Eur Respir J 2007; 29: 930-936.

Hawkins P, Johnson LC, Nikoletou D, et al. Proportional assist ventilation as an aid to exercise training in severe chronic obstructive pulmonary disease. Thorax 2002; 57: 853-859.

Vitacca M, Kaymaz D, Lanini B, et al. Non-invasive ventilation during cycle exercise training in patients with chronic respiratory failure on long-term ventilatory support: a randomized controlled trial. Respirology 2018; 23: $182-189$.

Dreher M, Doncheva E, Schwoerer A, et al. Preserving oxygenation during walking in severe chronic obstructive pulmonary disease: noninvasive ventilation versus oxygen therapy. Respiration 2009; 78: 154-160.

Menadue C, Piper AJ, van't Hul AJ, et al. Non-invasive ventilation during exercise training for people with chronic obstructive pulmonary disease. Cochrane Database Syst Rev 2014; 5: CD007714.

van't Hul A, Gosselink R, Hollander P, et al. Training with inspiratory pressure support in patients with severe COPD. Eur Respir J 2006; 27: 65-72.

Vitacca M, Ambrosino N. Non-invasive ventilation as an adjunct to exercise training in chronic ventilatory failure: a narrative review. Respiration 2019; 97: 3-11.

Schols AM, Broekhuizen R, Weling-Scheepers CA, et al. Body composition and mortality in chronic obstructive pulmonary disease. Am J Clin Nutr 2005; 82: 53-59.

Pan L, Wang M, Xie X, et al. Effects of anabolic steroids on chronic obstructive pulmonary disease: a meta-analysis of randomised controlled trials. PLoS One 2014; 9: e84855.

Camillo CA, Osadnik CR, van Remoortel $\mathrm{H}$, et al. Effect of "add-on" interventions on exercise training in individuals with COPD: a systematic review. ERJ Open Res 2016; 2: 00078-2015.

Sanders MH, Newman AB, Haggerty CL, et al. Sleep Heart Health Study. Sleep and sleep-disordered breathing in adults with predominantly mild obstructive airway disease. Am J Respir Crit Care Med 2003; 167: 7-14. 
111 Soler X, Gaio E, Powell FL, et al. High prevalence of obstructive sleep apnea in patients with moderate to severe chronic obstructive pulmonary disease. Ann Am Thorac Soc 2015; 12: 1219-1225.

112 Donovan LM, Feemster LC, Udris EM, et al. Poor outcomes among patients with chronic obstructive pulmonary disease with higher risk for undiagnosed obstructive sleep apnea in the LOTT cohort. J Clin Sleep Med 2019; 15: 71-77.

113 Pissulin FDM, Pacagnelli FL, Alda MA, et al. The triad of obstructive sleep apnea syndrome, COPD, and obesity: sensitivity of sleep scales and respiratory questionnaires. J Bras Pneumol 2018; 44: 202-206.

114 Soler X, Liao SY, Marin JM, et al. Age, gender, neck circumference, and Epworth sleepiness scale do not predict obstructive sleep apnea (OSA) in moderate to severe chronic obstructive pulmonary disease (COPD): the challenge to predict OSA in advanced COPD. PLoS One 2017; 12: e0177289.

115 Kitajima T, Marumo S, Shima H, et al. Clinical impact of episodic nocturnal hypercapnia and its treatment with noninvasive positive pressure ventilation in patients with stable advanced COPD. Int J Chron Obstruct Pulmon Dis 2018; 13: 843-853.

116 Egan TM, Murray S, Bustami RT, et al. Development of the new lung allocation system in the United States. Am $J$ Transplant 2006; 6: 1212-1227.

117 Schuba B, Scheklinski M, von Dossow V, et al. Five-year experience using the Lung Allocation Score: the Munich Lung Transplant Group. Eur J Cardiothorac Surg 2018; 54: 328-333.

118 Khush KK, Cherikh WS, Chambers DC, et al. The International Thoracic Organ Transplant Registry of the International Society for Heart and Lung Transplantation: Thirty-sixth adult heart transplantation report - 2019; focus theme: Donor and recipient size match. J Heart Lung Transplant 2019; 38: 1056-1066.

119 Langer D. Rehabilitation in patients before and after lung transplantation. Respiration 2015; 89: 353-362.

120 Mullerova $\mathrm{H}, \mathrm{Lu} \mathrm{C}, \mathrm{Li} \mathrm{H}$, et al. Prevalence and burden of breathlessness in patients with chronic obstructive pulmonary disease managed in primary care. PLoS One 2014; 9: e85540.

121 Janssen DJ, Wouters EF, Spruit MA. Psychosocial consequences of living with breathlessness due to advanced disease. Curr Opin Support Palliat Care 2015; 9: 232-237.

122 Bausewein C, Schunk M, Schumacher P, et al. Breathlessness services as a new model of support for patients with respiratory disease. Chron Respir Dis 2018; 15: 48-59.

123 Luckett T, Phillips J, Johnson MJ, et al. Contributions of a hand-held fan to self-management of chronic breathlessness. Eur Respir J 2017; 50: 1700262.

124 Ekstrom M, Nilsson F, Abernethy AA, et al. Effects of opioids on breathlessness and exercise capacity in chronic obstructive pulmonary disease. A systematic review. Ann Am Thorac Soc 2015; 12: 1079-1092.

125 Janssen DJ, de Hosson SM, bij de Vaate E, et al. Attitudes toward opioids for refractory dyspnea in COPD among Dutch chest physicians. Chron Respir Dis 2015; 12: 85-92.

126 O'Donnell DE, Webb KA, Harle I, et al. Pharmacological management of breathlessness in COPD: recent advances and hopes for the future. Expert Rev Respir Med 2016; 10: 823-834

127 Rietjens JAC, Sudore RL, Connolly M, et al. European Association for Palliative Care. Definition and recommendations for advance care planning: an international consensus supported by the European Association for Palliative Care. Lancet Oncol 2017; 18: e543-e551.

128 Brinkman-Stoppelenburg A, Rietjens JA, van der Heide A. The effects of advance care planning on end-of-life care: a systematic review. Palliat Med 2014; 28: 1000-1025.

129 Gershon AS, Maclagan LC, Luo J, et al. End-of-life strategies among patients with advanced chronic obstructive pulmonary disease. Am J Respir Crit Care Med 2018; 198: 1389-1396.

130 Bloom CI, Slaich B, Morales DR, et al. Low uptake of palliative care for COPD patients within primary care in the UK. Eur Respir J 2018; 51: 1701879.

131 Jabbarian LJ, Zwakman M, van der Heide A, et al. Advance care planning for patients with chronic respiratory diseases: a systematic review of preferences and practices. Thorax 2018; 73: 222-230.

132 Janssen DJ, Engelberg RA, Wouters EF, et al. Advance care planning for patients with COPD: past, present and future. Patient Educ Couns 2012; 86: 19-24.

133 Houben CHM, Spruit MA, Luyten H, et al. Cluster-randomised trial of a nurse-led advance care planning session in patients with COPD and their loved ones. Thorax 2019; 74: 328-336.

134 Alhazzani W, Guyatt G. An overview of the GRADE approach and a peek at the future. Med J Aust 2018; 209: 291-292. 